\title{
A framework for climate change engagement through video games
}

\section{Tania Ouariachi, María Dolores Olvera-Lobo, José Gutiérrez-Pérez \& Edward} Maibach

To cite this article: Tania Ouariachi, María Dolores Olvera-Lobo, José Gutiérrez-Pérez \& Edward Maibach (2018): A framework for climate change engagement through video games, Environmental Education Research, DOI: 10.1080/13504622.2018.1545156

To link to this article: https://doi.org/10.1080/13504622.2018.1545156

曲 Published online: 28 Dec 2018.

Submit your article to this journal $₫$

View Crossmark data \ulcorner 


\title{
A framework for climate change engagement through video games
}

\author{
Tania Ouariachi ${ }^{\mathrm{a}}$ (D), María Dolores Olvera-Lobo ${ }^{\mathrm{b}}$ (D), José Gutiérrez-Pérez ${ }^{\mathrm{c}}$ and \\ Edward Maibach $^{\text {d }}$ \\ ${ }^{a}$ Center of Expertise Energy, Hanze University of Applied Sciences, Groningen, The Netherlands; \\ ${ }^{b}$ Department of Information and Communication, Campus Cartuja, Universidad de Granada, Granada, Spain; \\ 'Department of Educational Methodology, Campus Cartuja, Universidad de Granada, Granada, Spain; \\ ${ }^{\mathrm{d}}$ George Mason University-Center for Climate Change Communication, Fairfax, Virginia, USA
}

\begin{abstract}
Video games have the potential to educate and engage people-especially young people-in climate change and energy issues by facilitating the development of helpful thoughts, feelings, and actions. The objective of the present article is to propose a set of game attributes that could maximise the cognitive, emotional, and behavioural engagement of players, and lay the foundations for future work. We have used semistructured interviews with experts to identify a set of game attributes and a group discussion with teenagers to validate them. By applying grounded theory in our analysis of the experts' responses, we have developed a framework for climate change engagement through serious games. It consists of 15 key attributes that we have classified in three dimensions: cognitive, emotional, and behavioural. Literature review drawn on sources in social psychology, communication and education has contributed to further explain and justify the inclusion of each of the attributes.
\end{abstract}

\section{ARTICLE HISTORY}

Received 1 November 2017

Accepted 1 November 2018

\section{KEYWORDS}

climate change; young people; video games; game-based learning; engagement; grounded theory

\section{Introduction}

Critical questions have been raised about the effectiveness of communication on the issue of climate change and on the effort invested into educating people about it (Moser 2010). Finding ways to effectively engage young people is particularly important: we need to prepare them to deal with the consequences of climate change; they can propose policy changes both now and in the future; and, potentially, they can change their own behaviour and effect change in that of their families (Boudet et al. 2014; Corner et al. 2015; Flora et al. 2014; Yang, Lin, and Liu 2016).

Schools are an obvious channel through which to engage young people in the key issues associated with climate change, although formal education about the issue is not without its challenges. These include the one-way communication models that separate transmitter and receiver; the lack of critical approaches, evidenced by the absence of spaces for reflection and debate on possible alternative lifestyles; and the lack of opportunities to participate in bringing about in-depth learning (Lombardi and Sinatra 2013; Plutzer et al. 2016; Stevenson, Peterson,

CONTACT Tania Ouariachi $\otimes$ t.ouariachi.peralta@pl.hanze.nl Professorship Communication, Behaviour \& the Sustainable Society, E Center of Expertise Energy, Hanze University of Applied Sciences, Zernikeplein 7, 9747 AS, Groningen, The Netherlands. 
and Bradshaw 2016). Furthermore, climate change is surrounded by 'fake news' promoted by sceptics, a phenomenon that has put teachers on the alert and encouraged them to embrace media literacy: 'the ability to access, understand, evaluate, and create media content' (Cooper 2011).

Given that the youth of today are an 'interactive generation', in the present article we focus on reaching them through interactive, digital entertainment media, specifically video gaming. Today, nearly all young people in OECD nations play video games. In a country like the United Kingdom, which has a strong gaming culture, by the age of 21 , the average young person will have spent $->10$ '000 hours playing online games (McGonigal 2011).

Recently, there has been an increase in the development of online climate change gamesthat is, online video games specifically themed around climate change and/or related topics (Wu and Lee 2015). The technical sophistication, narrative, message framing, game dynamics, and pedagogical features of these communication and education tools vary (Ouariachi, OlveraLobo, and Gutiérrez-Pérez 2017). They can be considered 'games for change', 'social impact games' or 'serious games', if they are intended to fulfil a purpose, convey ideas and values, and sometimes, to influence the players' thoughts and actions in real life (Frasca 2007). (In the present article, we use the terms 'video games' and 'serious games on climate change' interchangeably.)

This type of game has grown in popularity and more and more teachers have become increasingly interested in harnessing the potential of gaming strategies to advance climate change education. Well-designed games foster specific skills and abilities, contribute to the development of curricular content, and provide experiential learning, simulating unfamiliar circumstances that are impossible in real life (Gee 2004; Hamari et al. 2016). In Europe, under the paradigm of 'digital game-based learning', several projects using video games have been implemented successfully to address climate change in high schools (Flora et al. 2014; Knock and De Vries 2011).

In fact, scholars argue that serious games can be an effective tool to increase young people's engagement with climate change issues. This is said to occur because 'playing a game can lead to a state of flow or immersion where players are extremely concentrated and time passes unnoticed'. This can lead to greater awareness and understanding of important factors involved in the game (e.g. energy saving), and consequently, to a positive change in attitude which can later trigger a change in behaviour (Soekarjo and van Oostendorp 2015). However, to date, empirical findings on the effectiveness of serious games on climate change issues have been contradictory. Some authors report positive effects on awareness, knowledge, attitudes or behaviour whereas others have found only limited or no effect (Soekarjo and van Oostendorp 2015; Yang, Lin, and Liu 2016). Nonetheless, these studies do agree on the importance of video game design as one of the main factors contributing to their effectiveness.

Therefore, it is important to determine the specific attributes of those video games most likely to engage young people and create in them a personal state of connection with climate change? Ideally, these video games would facilitate the development of helpful thoughts, feelings and actions in the fight against climate change. Consequently, the objective of the present paper is to empirically determine the attributes of a climate change game that would make the most impact on user engagement at the cognitive, emotional, and behavioural levels. To achieve this, we have conducted semi-structured interviews with experts $(n=12)$ to identify a set of attributes. We then validated these through a group discussion with teenagers aged from 12 to $18(n=17)$ and located adequate support through our literature review. We applied grounded theory-a qualitative methodology applied in psychology - in our analysis of the interview responses and group discussion and used it to develop a framework to analyse and create video games that would inspire climate change mitigation and climate change adaptation. 


\section{Defining engagement}

In social science research, the concept of engagement has many connotations. These include narrative engagement, which is related to the feelings experienced when engaging with audiovisual narratives on television or in the cinema (Busselle and Bilandzic 2009); and player engagement, which is related to the experience of playing games and linked to a multitude of other concepts such as Flow (Csikszentmihalyi 1991), Immersion (Brown and Cairns 2004), or Motivation (Yee 2006). For this study, we have taken the concept of engagement used in climate change communication literature, specifically that outlined by Lorenzoni, Nicholson-Cole, and Whitmarsh (2007), who define engagement with climate change as '[the] individuals' evaluation of and response to climate change which compromises cognitive, emotional and behavioural components'. We have chosen this approach because it is directly connected to the aim of our study, providing an initial framework to categorise those attributes of video games that create a personal connection with the issue of climate change. Contemporary research into video games deals with these variables from a theoretical perspective.

Lorenzoni, Nicholson-Cole, and Whitmarsh (2007) suggest it is not enough for people to know about climate change in order to become engaged, 'they also need to care about it, be motivated and able to take action'. Hence, our definition of engagement encompasses the three dimensions: the cognitive, the emotional and the behavioural. So, in order to become more engaged with climate change issues, players will: (a) think more and possibly learn more about the issue; (b) feel more personally involved-that is, they will accord the issue greater importance; and (c) make behavioural changes to express their concern. These characteristics were the basis of our interviews and the group discussion.

The relation between the three dimensions of engagement is complex: people may adopt a number of different roles in climate change mitigation and adaptation, ranging from active engagement to passive compliance. Whitmarsh et al. (2013) define these roles as low-carbon consumers, low-carbon citizens, and low-carbon champions. The rationale for engagement with climate change varies too, and different groups (governments, businesses, non-governmental organisations, and so on) have different interests and discourses for taking an interest in people's understanding of and responses to climate change.

\section{Methodological approach}

This study takes a qualitative, interpretative approach to data collection and analysis. We use grounded theory (Charmaz 2006; Glaser and Strauss 1967; Strauss and Corbin 1990) to develop a framework for climate change engagement through serious games 'grounded' on data collected in semi-structured interviews with key experts, intended to help us identify game attributes. The findings of our interviews were then corroborated by a group discussion with teenagers (consensus validity) and supported by our literature review (content validity).

As Hook (2015) explains, the process of grounded theory starts with data collection, gradually building up categories - the exploratory phase-and then forming a theory before corroborating and linking it to the literature-the theorising and validating phase (Figure 1). The process is not linear. Typically, interpretative research is cyclical and analysis involves repeatedly returning to and revising data to strengthen classifications (Gutiérrez-Pérez, Pozo-Llorente, and FernándezCano 2002).

In the field of games, grounded theory has earlier been implemented to investigate the players' wish to keep on playing (Schoenau-Fog 2011) or the process of immersion (Brown and Cairns 2004). In environmental education, it has been used to build an environmental field days observation tool (Heimlich, Carlson, and Storksdieck 2011). 


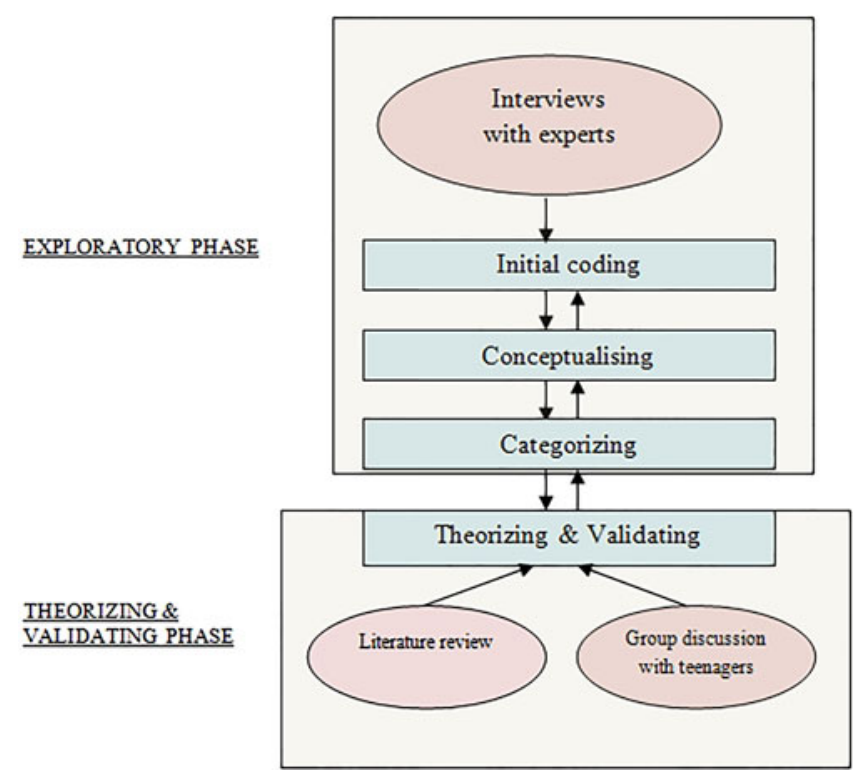

Figure 1. Methodological approach in this study.

\subsection{Interview sampling and procedures}

Qualitative research makes no external statistical generalisations because its goal is not to make 'inferences' about the underlying population but to attempt to obtain insights into a particular phenomenon (Connolly 1998). Hence, researchers purposefully select individuals (purposive sampling) in order to increase their understanding of phenomena (Onwuegbuzie and Leech 2007). We have used an initial list of experts compiled by targeted Internet searches. Our search criteria were (a) that the experts were involved in developing climate change games, and (b) that they were well-known game designers and scholars. We then asked the selected experts to recommend others who also matched our criteria (snowball sampling).

The selected experts were contacted by e-mail and invited to participate in an interview. We sent up to two follow-up e-mails to invite those who did not initially respond to participate. Of the 18 experts selected and invited, 12 responded positively: five women and seven men, all from the US. Of these 12 interviewees, two work for federal agencies (EPA, NOAA), one for a scientific magazine (National Geographic), one for an NGO (Red Cross Red Crescent Climate Center), two work at research centres (Wilson Center, Virginia Serious Games Institute-GMU), and six for game design companies (Legacy Games, Game Lab, Sense of Wonder, Persuasive Games, Schell Games, Wyvern). Our experts have been involved in developing games on climate change or sustainability issues (Disaster Hero, Recycle City, SimCityEDU, Decisions for the Decade, Paying for predictions, Act to Adapt, Windfall, Where the Rivers Meet the Sea, and Plant it Green).

The 12 semi-structured interviews were conducted face-to-face or by telephone/email when this was impossible. After the 12 interviews, we decided there was little purpose in extending our search to locate other experts because we had encountered no substantial additional information (i.e. data saturation). This was consistent with qualitative research practice in conducting interviews (Onwuegbuzie and Leech 2007).

To gather contextual information, the interviewees were asked general questions about their current projects and about the opportunities and risks of using online climate change games as communication and education tools to engage young people. They were then asked which attributes a serious game on climate change should have in order to make the 
strongest impact on users' cognitive, emotional and behavioural engagement. On average, interviews lasted 40 minutes (range 30-50 minutes). All interviews were recorded and transcribed immediately. Interview transcripts were reviewed and underwent two rounds of summary and editing.

\subsection{Group discussion sampling and procedures}

To validate our results and test our interview-generated hypothesis by checking for agreement and consensus, the same researcher who had conducted the interviews led a group discussion with 17 students aged from 12 to 18 years. We chose young people because they are the target user group for most climate change serious games currently being developed (Ouariachi, OlveraLobo, and Gutiérrez-Pérez 2017).

The group included students of all ages between 12 and 18 years, both male and female, and from different socio-economic backgrounds. As mentioned earlier, in exploratory qualitative studies, the purpose of a representative or meaningful sample is not to serve as a generalisation of a given population but, rather, to increase our understanding of a specific phenomenon; hence our decision to use purposive sampling. Our student group came from a school selected because of: (a) the academic director's interest in the students' participation in this study and in our making use of the findings for academic purposes; (b) the willingness of teachers to participate in the process and facilitate logistics; and (c) the approval of the academic board and parents.

The group discussion took place during a scheduled class. The researcher acted as moderator, with support from the teacher, and introduced the objectives and explained how the discussion would proceed. They then asked participants to imagine they were working for a game design company and that their company had been asked to make a serious game about climate change. The participants next had to brainstorm, discuss and write down game attributes that would engage players, create emotional investment, and inspire players to make real-life changes based on what they had learned in the game. The students also wrote down additional game attributes they thought could support the three dimensions of the game, and continued sharing ideas with their classmates.

The outcomes of this group discussion were added to the description of each of the game attributes proposed, offering vivid examples to further support our findings from the expert interviews.

\section{Description of the analytical process}

Although the present paper has a clear linear structure, our research analysis has followed an iterative pattern. Having introduced our data collection process earlier, we will now reflect on the coding procedures leading to the construction of categories-omitting a detailed overview of the complete set of codes-and on the theorising and validating process.

\subsection{Initial coding}

We first selected those passages of discourse that represented ideas. Then, we used a line-byline coding technique, which consisted of naming each line of data from a critical, analytical perspective. To do so, we used both explicit and latent codes that were relevant and significant to the phenomenon studied and the development of our theory. We then wrote 'memos' on these in the margins of the field notes. Given that this is a social constructivist approach, it was crucial that researchers were aware of any preconceived notions and biases which might affect their 'construction' of the subsequent theory.

In total, we adopted 56 codes: achievement, doing well, winning, possible, realistic, challenge, problem, attention on gameplay, text avoidance, statistics avoidance, concepts, expert, sense of 
Table 1. Example of passages and corresponding codes.

\begin{tabular}{|c|c|}
\hline Cognitive engagement & Code \\
\hline $\begin{array}{l}\text { The science background provided in climate games should be } \\
\text { from a trusted science expert, the content should have } \\
\text { multiple levels so that the players confront more challeng- } \\
\text { ing scenarios as they level up, and there must be a way to } \\
\text { "win". No one wants to play a game that they cannot win. }\end{array}$ & $\begin{array}{l}\text { Experts } \\
\text { Levels } \\
\text { Challenge } \\
\text { Winning }\end{array}$ \\
\hline $\begin{array}{l}\text { You present a conflict that you have to resolve and then you } \\
\text { go to the next conflict, over and over again. Offer them in } \\
\text { different levels, in chunks. Stay away from statistics and } \\
\text { focus on impacts they can understand. Active learning } \\
\text { components are subconscious: the character in a game } \\
\text { has to find the clues and then interact to pass to the } \\
\text { next level. }\end{array}$ & $\begin{array}{l}\text { Levels } \\
\text { Statistics avoidance } \\
\text { Impact } \\
\text { Subconscious }\end{array}$ \\
\hline Emotional engagement & Code \\
\hline $\begin{array}{l}\text { It's key to tie aspects of climate change to things the player } \\
\text { cares about - things close to home that are a part of their } \\
\text { everyday life. }\end{array}$ & $\begin{array}{l}\text { Care } \\
\text { Local } \\
\text { Ordinary }\end{array}$ \\
\hline $\begin{array}{l}\text { Make what they're doing feel important. Save animals, get } \\
\text { the chance to see what the world would look like if noth- } \\
\text { ing is done... etc. CC is a serious issue, so the emotional } \\
\text { involvement should be there... it's just the game's job to } \\
\text { unlock that. How? Written feedback, hearing from a person } \\
\text { that you "helped" in the game and how, etc. }\end{array}$ & $\begin{array}{l}\text { Feeling important } \\
\text { Emotional involvement } \\
\text { Feedback }\end{array}$ \\
\hline Behavioural engagement & Code \\
\hline $\begin{array}{l}\text { The behavioural change has to be within reach for the player, } \\
\text { and then they have to be able to see exactly what they } \\
\text { can do to change it, and then they have to be supported } \\
\text { in developing that habit and get positive feedback for it. } \\
\text { This has to be maintained over time in a loop and it has } \\
\text { to be socially connected to people they value / }\end{array}$ & $\begin{array}{l}\text { Possible } \\
\text { Modelling } \\
\text { Feedback } \\
\text { Social }\end{array}$ \\
\hline $\begin{array}{l}\text { Stepped engagement; Player can be successful at least at } \\
\text { beginning levels; Providing an engaging challenge that is } \\
\text { meaningful and connects with students' previous know- } \\
\text { ledge and experiences }\end{array}$ & $\begin{array}{l}\text { Levels } \\
\text { Challenge } \\
\text { Meaningful }\end{array}$ \\
\hline
\end{tabular}

agency, empowering, feeling good, feeling important, desired uncertainty, goals, subconscious, feedback, addictive, fun, aesthetics, characters, culture, personal, customised, levels, ramp-up, care, interest, concern, impact, emotional involvement, resonate, ordinary, local, fantasy, narrative, story, rewards, connections, relationships, comparisons, choices, complexity, consequences, multi-outcomes, simulation, modelling, puzzle, community, hybrid-reality, media, and pressure. The following examples come from the initial coding phase (Table 1).

In order to access a fast, visually rich approach to our basic understanding of the data at hand, we created word clouds ( Figures 2, 3,4) using TagCrowd software. These enabled us to visualise the text and highlight the more frequently used words by according them greater prominence in the image (McNaught and Lam 2010). Word clouds have been found useful in preliminary analysis elsewhere (Cidell 2010; McNaught and Lam 2010; Pendergast 2010).

Note that although the interviewees work in different types of organisation, their responses show many similarities.

\subsection{Conceptualising}

Our next step was to group the codes semantically in order to form broad concepts. In grounded theory analysis this is called focused coding and is more 'directed, selected and conceptual' than the first coding phase. It entails sifting through the line-by-line codes to find those that are most frequent and significant in order to synthesise and group the data (Charmaz 2006). Importance is accorded to commonality-frequency of appearance-extensiveness- 


\section{action attention challenging crocos concepts \\ connections consequences content experts \\ impacts information learn level \\ puzzle real sums subjectsystem think}

Figure 2. Word cloud for cognitive engagement.

\section{care change character \\ emotional feel help humans \\ important involvement wo narrative \\ person problem rewaw rewards}

Figure 3. Word cloud for emotional engagement.

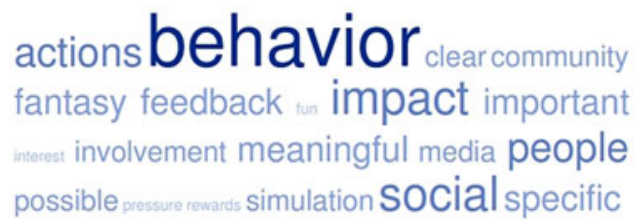

Figure 4. Word cloud for behavioural engagement.

representation of an issue across messages-and intensity-force of expression (Hass et al. 2010). This constant process of comparison is an integral part of grounded theory analysis (Glaser and Strauss 1967).

At this stage, grouping similar codes led to the emergence of the following concepts: accomplishment (achievement, doing well, winning); feasible (possible, realistic); simplicity (text avoidance, statistics avoidance); confidence (feeling good, feeling important); sense of control (sense of agency, empowering); tailored (personal, customised); proximity (ordinary, local); impactful (care, interest, concern, impact, emotional involvement, resonate); story-telling (narrative, story); associations (connections, relationships, comparisons); effects (consequences, multi-outcomes); and imitation (simulation, modelling).

\subsection{Categorising}

Finally, concepts were integrated into more inclusive core categories. Theoretical coding is an integrative process which involves a more sophisticated level of coding; it builds on the codes selected in the focused coding process, drawing relationships between them and making the analysis more coherent (Charmaz 2006). As in the earlier stage, data is constantly compared and researchers reflect on the original texts and memos. The resulting 15 core categories represent the interviewees' proposed set of game attributes (Table 2).

\subsection{Theorising}

The last step in our analysis focused on finding connections between the categories so that an integral framework would emerge. If we regard serious games as persuasive-based systems, the driving force for climate change would be engagement. Once we had identified the game attributes, we classified them within the three dimensions of engagement proposed by Lorenzoni, Nicholson-Cole, and Whitmarsh (2007): 
Table 2. Core categories -accompanied by their concepts- proposed as game attributes.

- Achievable: accomplishment, feasible

- Challenging: challenge, problem

- Concrete: attention to gameplay, simplicity

- Credible: concepts, experts

- Efficacy-enhancing: confidence, sense of control

- Experiential learning: desired uncertainty, focused goals, subconscious

- Feedback-oriented: feedback

- Fun: fun, addictive

- Identity-driven: aesthetics, characters, culture, tailored

- Levelling-up: levels, ramp-up

- Meaningful: impactful, proximity

- Narrative-driven: fantasy, storytelling

- Reward-driven: rewards

- Simulating: associations, choices, complexity, effects, imitation, puzzle

- Social: community, hybrid-reality, media, pressure

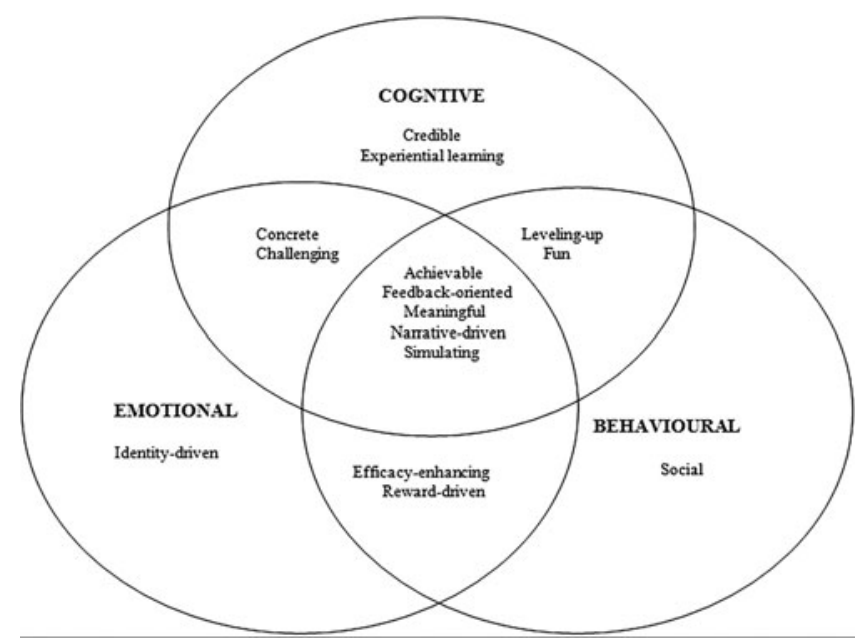

Figure 5. Framework of climate change engagement through video games.

- Cognitive involvement: what people think and know, and how much mental effort they are willing to make.

- Emotional involvement: what and how strongly people feel about climate change.

- Behavioural involvement: what and how much people do to address climate change.

Figure 5 shows the different categories that emerged and their inter-relationships in our attempt to generate an exploratory theory about climate change engagement through video games. As can be observed, some interviewees had difficulties separating game attributes into the three dimensions, since they all occur simultaneously. Hence, some attributes fall into two or all three dimensions.

The framework is composed of three dimensions and 15 attributes. It suggests that in order to create inspiring video games on climate change, there is a need to appeal, not only to the analytical processing system, but to the overall experiential system, playing with reality by creating imaginary worlds and highlighting powerful and emotive narratives about climate change that connect with young people's values and personal experiences, and paying careful attention to both verbal, written and audio-visual communication. An engaging game should be fun and should let the players work hard towards clear, achievable goals, connecting specific actions with specific consequences, giving players the chance to move through the game at their own pace, 
Table 3. Feedback from teenagers and relation with core categories.

\begin{tabular}{|c|c|}
\hline $\begin{array}{l}\text { Cognitive engagement } \\
\text { - } \quad \text { personal obstacles and time limit } \\
\text { - } \quad \text { advice from experts } \\
\text { - } \quad \text { different puzzles } \\
\text { - } \quad \text { let players make their own meaningful choices } \\
\text { - } \quad \text { teaching them in an exciting way } \\
\text { Emotional engagement } \\
\text { - } \quad \text { in-game connection with emotions, such as family } \\
\text { - } \quad \text { ry to save the world (important, change, help) } \\
\text { - } \quad \text { main character should be cute or you or first person } \\
\text { - } \quad \text { realise the consequences of actions. E.g.: show indicators } \\
\text { Behavioural engagement } \\
\text { - } \quad \text { real life appeal } \\
\text { - interact with other } \\
\text { - } \quad \text { have your character be able to level up } \\
\text { - } \quad \text { tell players to apply what they learn in the game to do in real life } \\
\text { - } \quad \text { show consequences of actions }\end{array}$ & $\begin{array}{l}\text { Relationships with core category } \\
\text { - } \quad \text { challenging } \\
\text { - } \quad \text { credial } \\
\text { - } \quad \text { challenging } \\
\text { - } \quad \text { meaningful, efficacy-enhancing } \\
\text { - } \quad \text { experiential learning, concrete } \\
\text { Relationships with core category } \\
\text { - } \quad \text { meaningful } \\
\text { - } \quad \text { meaningful } \\
\text { - } \quad \text { rewarrative-driven, identity-driven } \\
\text { - } \quad \text { simulating } \\
\text { Relationships with core category } \\
\text { - } \quad \text { achievable, meaningful } \\
\text { - } \quad \text { ocial } \\
-\quad \text { levelling-up } \\
\text { - } \quad \text { social (hybrid-reality) }\end{array}$ \\
\hline
\end{tabular}

providing them with positive evaluations and making them feel good, important or empowered to fight against climate change, whether they act in utopian or dystopian scenarios, or represent the 'good guys' or the 'bad guys'. When social interaction and peer pressure become involved, actions are more likely to be extrapolated from the virtual world to the real world, building a social movement.

\subsection{Validating}

In order to corroborate the components of the framework, we held a group discussion with teenagers. At this stage, we employed theoretical sampling, that is, we collected further data on the basis of the categories that had previously emerged. The results of the group discussion largely agreed with the experts' views on relevant game attributes. Both experts and teenagers proposed similar attributes and, even more interestingly, placed these within the same dimensions. The following table summarises their feedback and shows the relationships between their responses and the core categories (Table 3). No further core categories were identified and we therefore concluded we had reached theoretical saturation and achieved consensus validity on the proposed framework.

Next, we will explain each of the major categories by using interviewee responses and feedback provided by teenagers during the group discussion. The retention of original data and selection of examples serves as evidence of the categories. In addition, our review of research in psychological and communication sciences helps provide coherence to the findings and content validation for the proposed framework.

\section{Understanding the proposed attributes in the framework}

\subsection{Achievable: promoting possible actions within the reach of the individual}

The challenges presented to players in gameplay, as well as the behavioural change promoted in the messages have to be within the players' reach (Weitze 2014). According to the experts interviewed, at the cognitive and emotional levels, players should be able to perform well in the game and receive positive feedback when the goal is achieved, making them feel good about solving a difficult problem; at the behavioural level, the behaviour encouraged should be specific, possible, and easy to practice in the real world. 


\subsection{Challenging: a task that requires effort to perform}

Providing a challenge or a problem to solve that connects with young people's previous knowledge and experience can engage players cognitively and emotionally, according to our experts. The game should be at the appropriate level of difficulty for the player to be pushed to the limit of their capacity-designers usually make games too easy or too hard (McGonigal 2011). Variable difficulty, randomness or having hidden information can excite curiosity as can letting players advance in a game, whether literally in the exploration of a visual universe, conversations or events in adventure games, or in the relations between variables and the dynamics of the underlying system in strategy games.

\subsection{Concrete: simple messages, avoiding long text and statistics}

People simplify concepts and our task should be to help them simplify appropriately (Heath and Heath 2010). Experts agree that most climate change games fail because they focus too much on analysis, portraying too many numbers from the very beginning. In addition, walls of text should be avoided and information should be better integrated into the game mechanics. As one interviewee said: 'make sure their attention is focused on the gameplay itself'.

\subsection{Credibility: trustworthy information and aspirations}

Credibility helps you believe ideas, so the scientific background and concepts provided in climate games should come from trusted sources (Heath and Heath 2010). It is important to take account of those institutions or figures that our target audience consider most reliable. For instance, a study conducted among residents of Virginia (USA) revealed that TV weather forecasters are among the most trustworthy sources of information. The teenagers suggested games could incorporate trustworthy scientific sources or avatars and characters that represent sources our audience consider reliable (e.g. TV weather forecasters).

\subsection{Efficacy-enhancing: promoting a feeling of empowerment}

The global nature of the climate change problem tends to make people feel powerless. A sense of agency and control could therefore foster emotional and behavioural engagement (ONeill and Nicholson-Cole 2009; van der Linden, Maibach, and Leiserowitz 2015). Games should allow players to make their own decisions and see the consequences; after playing, players should feel inspired and confident to take action, aware that, for instance, they can minimise sea level rise, the threat to ecosystems and the impact to our health and well-being. During the group discussion, one teenager advised us to explicitly tell players to apply what they learn virtually in the game to the physical world, while one expert suggested providing messages, such as 'you can join this global movement by ...' or 'you can donate to this organization...' at the end of the game.

\subsection{Experiential learning: doing rather than thinking}

The last 25 years of research in cognitive psychology have shown that the human brain relies on two processing systems: System 1 is often described as experiential, intuitive, automatic, affective, and fast; while System 2 is deliberate, effortful, rational, and slow (Kahneman 2012). In practice, the human brain gives priority to experience over analysis (van der Linden, Maibach, and Leiserowitz 2015). Because of the emotional pathways it triggers and because climate change can be considered an 'invisible' process, experience can be a powerful 'teacher', which is why 
games are great tools since they can provide 'designed experiences' in which players can learn through reflection on doing and being (Wu and Lee 2015). Experts think the key is to have clear learning goals and then work from there. They also highlight the importance of 'subconscious' learning by introducing concepts piecemeal in a way that makes sense in the narrative that drives the game: 'young people do not like their games to preach at them, so designers should gently nudge players towards the message they want to impart', said one interviewee.

\subsection{Feedback-oriented: evaluation of current performance relative to a goal}

Effective feedback is considered central to the efficacy of cognitive, emotional and behavioural engagement. Verbal or written feedback is more effective when it provides sufficient, clear and specific information to achieve goals and is presented at a time relatively close to that of the event being evaluated (Prensky 2001). Our panel of experts suggests that the consequences of decisions and actions taken in the game could be the feedback that you want the players to receive and replicate in real life, and this feedback should be positive and encouraging.

\subsection{Fun: amusement that hooks}

Despite the 'serious' tag, the experts consulted agreed that the ideal climate change game should involve a certain degree of fun and entertainment. Players are more likely to play the game several times, which will keep the issue at the forefront of their minds. Some authors suggest that games can be more fun when you can act and be like your ideal self: gaming is the ideal platform for people to 'try on different hats' and take on a desired characteristic (Przybylski et al. 2012). One interviewee even suggested that a game could promote behaviour that is the opposite of that desired, playing the 'evil' side.

\subsection{Identity-driven: connections to relevant personal experiences}

Games should appeal to players' identities, not only to the people they are right now, but also to the people they would like to be (Heath and Heath 2010). Creating inspiring characters that players care about and can help could be a powerful strategy to achieve an emotional connection in the game since they can reflect the human aspects of climate change. These characters can represent the players themselves (first-person game), but also other identities. Giving players choices to customise characters by, for instance, choosing the name and icon representing them can also result in increasing the personal connection.

\subsection{Levelling-up: long term goal-directed behaviour facilitated by clear milestones}

Experts and teenagers agree that games should begin with simpler levels and become more complex while playing, maintaining the skill gap by moving through the game at their own pace. The game should have multiple levels, so that players confront more challenging scenarios as they level up. Additionally, players could re-play levels to practice skills before moving on to more difficult levels (Morris et al. 2013). Levelling is also important to motivate behavioural change because people feel more confident and closer to the finish line than they might have thought (Heath and Heath 2010).

\subsection{Meaningful: evoking intense feelings}

Knowing about climate change is not enough; it is necessary to make people feel its impact in order to increase their attention, interest and willingness to take action. There is no magic 
formula to find the right emotive aspects of a game; however, research in the field of climate change communication has revealed that if imagery and messages in the game increase worry or fear, these should be accompanied by feelings associated with remedial action and solutions, linking to individuals' everyday emotions in the context of climate change; otherwise, it can make them feel helpless and overwhelmed (ONeill and Nicholson-Cole 2009; Parant et al. 2017).

\subsection{Narrative-driven: stories or accounts of events}

Many of our expert interviewees considered the game narrative to be a key strategy to achieve engagement. Narratives can facilitate, for instance, cognitive processes like concretising and assimilation, the arousal of feelings, the connections with people's deepest motivations and the promotion of meaningful actions. Stories can engage players in their emotions, values and imaginations, which are the drivers of change (Dahlstrom 2014). Some argue that many climate change games have failed because they did not create a fantasy that was meaningful for the player. The point of playing a game is to indulge in fantasy: even if the game is reality-based, our role is not. The group discussion with teenagers revealed the importance they assign to fantasy. Some of them talk about 'post-apocalyptic dystopia' and offer the following examples:

The world is destroyed by climate change. Almost everyone is dead and the ones left have to wear gas masks. Your job is to go around the world and repair it, but you have to face a group of bad guys who are trying to stop you.

Some experts maintain that routing the player into any kind of linear narrative is not convenient and recommend focusing attention on creating a system that can produce multiple outcomes. Some teenagers talk about 'open worlds'.

\subsection{Reward-driven: return for performance of a desired task}

Giving rewards to players when passing levels or meeting game targets, such as reducing greenhouse emissions or planting trees can drive engagement, if the game structure is sufficiently compelling and rewards are truly meaningful to the player, according to our experts. Rewards can increase the frequency of behaviour, both virtually and in reality (Mitgutsch and Alvarado 2012; Morris et al. 2013). These can be high scores, as suggested by teenagers, but also badges, awards, levels, or leader boards.

\subsection{Simulating: modelling reality by creating imaginary worlds}

A challenging puzzle that simulates experiences for the players can be a strong component of engagement. Simulations allow individuals to play with reality by creating imaginary worlds where they can do things that they otherwise cannot. Both the experts and the teenagers recognise that games can connect and associate specific actions with specific consequences, especially since they resonate in far wider spaces and at more distant times than the player can conceive of in ordinary life. Experts encourage designers to create 'multi-outcome oriented systems' for climate change games, ensuring the player is faced with a range of choices. By manipulating different variables, the system can create multiple (but specific) outcomes. It is by exploring these outcomes that players can learn about complexity (Morris et al. 2013).

\subsection{Social: activating networking}

Our interviews reveal that socialising is a key game attribute that achieves behavioural engagement. Humans have evolved while living in communities, and it is through interaction, 
comparison, and social pressure that we validate our actions (van der Linden, Maibach, and Leiserowitz 2015). Other suggested strategies include competing or helping others in the game; chatting with other players; being part of a group effort; integrating social media like Facebook into the game; using leader boards; and embedding the game into learning environments or social settings. Combining missions inside and outside of the game could be another strategy, for instance, by making use of geo-locations. Location-based games or alternate reality games bridge digital and physical spaces while encouraging players to socialise (Chess and Booth 2014; De Souza e Silva and Delacruz 2006; Schneider and Schaal 2017).

\section{Discussion and conclusion}

Well-designed video games offer new opportunities to engage young people with the issue of climate change and encourage them to think, feel and act in ways that help address the problem. The framework presented here, composed of three dimensions and 15 attributes, is based on input from game design experts and students and provides an initial basis on which to create and analyse climate change games to engage 'digital natives' cognitively, emotionally, and behaviourally. The lines between the game attribute dimensions are blurred, since they can fall in different, or even all, dimensions (cognitive, emotional, and behavioural), as our preliminary analysis through word clouds demonstrated. Interestingly, there was a high degree of convergence among experts and students about those game attributes that effectively engage young people.

On the basis of our experts' responses (and those of the students), we can assume that there is a preference for constructivism, facilitating a multi-outcome oriented system in which the learning experience draws on different perspectives, gives rise to a variety of actions and offers fuller understanding of the topic. Conversely, they felt that a 'drill-and-practice' approach (based on information transmission) is not sufficient to engage players; players must actively engage in the game and construct their own knowledge.

We firmly believe that further research in this field should be encouraged. Further research could involve testing the framework proposed here on currently existing climate change games by, for instance, developing a checklist for analysts to indicate the presence or absence of any of the 15 attributes and show examples for each of them; developing new games-or modifying existing games-and making use of these attributes during the design process to test the cognitive, affective and behavioural impact of the proposed dimensions, individually or as a package; and testing boundary conditions such as age (e.g. children versus teenagers versus adults), topics (e.g. health games versus other environmental games), and populations (individual versus collective cultures).

Notwithstanding, the present study is somewhat limited due to its constructionist, interpretative approach and to the active role of the researchers in 'constructing' categories, even though the theory is 'grounded' in empirical data. It has been our intention to address this issue by adding consensus and content validity to the framework, as well as reaching theoretical saturation. Our analysis shows strong links between codes, concepts and categories, and that arguments are put forward in a coherent manner. In that sense, we constantly compare elements to examine the codification, decide if the data is consistent with previous classifications, and promote a more reflective analysis of the data. Even though this exploratory study is not intended to generalise data to a population but to increase our understanding of a specific phenomenon, we feel obliged to mention the limited sample size and the method used for the interviews and group discussion. Having said that, we would encourage researchers to replicate this study with larger and more diverse samples to corroborate or refute our findings.

In conclusion, we hope this approach offers new insights and lays the foundations for further research. 


\section{Disclosure Statement}

No potential conflict of interest was reported by the authors.

\section{Notes on contributors}

Tania Ouariachi $(\mathrm{PhD})$ is a lecturer and researcher at Hanze University of Applied Sciences in Groningen in The Netherlands. She also belongs to the Research Group "Scientific Information: Access and Evaluation" at University of Granada in Spain. Her research focuses on video games and climate change educommunication. She has experience working as a journalist and as a communication specialist for scientific institutions.

María Dolores Olvera-Lobo (PhD) is a professor in the Department of Information and Communication and the Department of Library and Information Science at the University of Granada in Spain. She is Director of the Research Group "Scientific Information: Access and Evaluation" and belongs to CSIC-Unidad Asociada Grupo SCImago. Her research interests are information retrieval, information science, new technologies, and gamification.

José Gutiérrez-Pérez (PhD) is a professor in the Department of Educational Methodology at the University of Granada in Spain. He is Director of the Research Group "Evaluation in Environmental, Social and Institutional Education" and Head of Institutional Evaluation and Accreditation of the Andalusian Agency Knowledge. Current research interests are environmental education, gaming evaluation methods, and climate change perceptions.

Edward Maibach (PhD) is distinguished professor and Director of Mason's Center for Climate Change Communication (4C). His research currently focuses exclusively on how to mobilise populations to adopt behaviors and support public policies that reduce greenhouse gas emissions and help communities adapt to the unavoidable consequences of climate change.

\section{ORCID}

Tania Ouariachi (D) http://orcid.org/0000-0003-4472-4767

María Dolores Olvera-Lobo (iD http://orcid.org/0000-0002-0489-7674

\section{References}

Boudet, H., N. M. Ardoin, J. Flora, K. C. Armel, M. Desai, and T. N. Robinson. 2014. "Energy Behaviours of Northern California Girl Scouts and Their Families." Energy Policy 73:439-49. doi: 10.1038/NENERGY.2016.91

Brown, E., and P. Cairns. 2004. A Grounded Investigation of Game Immersion. Paper presented at the Conference on Human Factors in Computing Systems of Vienna.

Busselle, R., and H. Bilandzic. 2009. "Measuring Narrative Engagement." Media Psychology 12 (4):321-47. doi: 10.1080/15213260903287259

Charmaz, K. 2006. Constructing Grounded Theory. London: Sage Publications.

Chess, S., and P. Booth. 2014. "Lessons down a Rabbit Hole: Alternate Reality Gaming in the Classroom." New Media \& Society $16(6): 1002-17$.

Cidell, J. 2010. "Content Clouds as Exploratory Qualitative Data Analysis." AREA 42 (4):514-23.

Connolly, P. 1998. "Dancing to the Wrong Tune': Ethnography Generalization and Research on Racism in Schools." In Researching Racism in Education: Politics, Theory, and Practice, edited by P. Connolly and B. Troyna, 122-39. Buckingham, UK: Open University Press.

Cooper, C. B. 2011. "Media Literacy as a Key Strategy towards Improving Public Acceptance of Climate Change Science." BioScience 61 (3):231-7. doi:10.1525/bio.2011.61.3.8 PubMed

Corner, A., O. Roberts, S. Chiari, S. Völler, E. S. Mayrhuber, S. Mandl, and K. Monson. 2015. "How Do Young People Engage with Climate Change? the Role of Knowledge, Values, Message Framing, and Trusted Communicators." Wiley Interdisciplinary Reviews: Climate Change 6 (5):523-34. doi: 10.1002/wcc.353

Csikszentmihalyi, M. 1991. Flow: The Psychology of Optimal Experience. New York: Harper Row

Dahlstrom, M. F. 2014. "Using Narratives and Storytelling to Communicate Science with Non-Expert Audiences." Proceedings of the National Academy of Sciences of United States of America 111 (Supplement_4):13614-20.

De Souza e Silva, A., and G. C. Delacruz. 2006. "Hybrid Reality Games Reframed. Potential Uses in Educational Contexts." Games and Culture 1 (3):231-51. doi:10.1177/1555412006290443 
Flora, J. A., M. Saphir, M. Lappé, C. Roser-Renouf, E. W. Maibach, and A. A. Leiserowitz. 2014. "Evaluation of a National High School Entertainment Education Program: The Alliance for Climate Education." Climatic Change 127 (3-4):419-34. doi:10.1007/s10584-014-1274-1

Frasca, G. 2007. "Play the message: Play, game and video game rhetoric". PhD diss., IT University of Copenhagen, Copenhagen, Denmark. Retrieved from http://www.powerfulrobot.com/Frasca_Play_the_Message_PhD.pdf

Gee, J. P. 2004. What Video Games have to Teach us About Learning and Literacy. Archidona, Spain: Aljibe.

Glaser, B., and A. Strauss. 1967. The Discovery of Grounded Theory: Strategies for Qualitative Research. London: Cambridge University Press.

Gutiérrez-Pérez, J., T. Pozo-Llorente, and A. Fernández-Cano. 2002. "Los Estudios de Caso en la Lógica de la Investigación Interpretativa." Arbor CLXXI (675):533-57.

Hamari, J., D. Shernoff, E. Rowe, B. Coller, J. Asbell-Clarke, and T. Edwards. 2016. "Challenging Games Help Students Learn: An Empirical Study on Engagement, Flow and Immersion in Game-Based Learning." Computers in Human Behavior 54:170-9. doi: 10.1016/j.chb.2015.07.045 0747-5632

Hass, S. M., E. I. Meghan, N. A. Jennings, and L. M. Wagner. 2010. "Communicating Thin: A Grounded Model of Online Negative Enabling Support Groups in the Pro-Anorexia Movement." New Media \& Society 13 (1):40-57. doi: $10.1177 / 1461444810363910$

Heath, C., and D. Heath. 2010. Switch: How to Change Things When Change Is Hard. New York: Broadway Books.

Heimlich, J. E., S. P. Carlson, and M. Storksdieck. 2011. "Building Face, Construct, and Content Validity through Use of a Modified Delphi: adapting Grounded Theory to Build an Environmental Field Days Observation Tool." Environmental Education Research 17 (3):287-305. doi: 10.1080/13504622.2010.538669

Hook, N. 2015. "Grounded theory". In Game Research Methods: An Overview, edited by Lankoski, P. and S. Bjork, 309-20. Pittsburgh, PA: ETC Press.

Kahneman, D. 2012. Thinking, Fast and Slow. New York, NY: Farrar, Straus and Giroux

Knock, E., and P. W. De Vries. 2011. "EnerCities, a Serious Game to Stimulate Sustainability and Energy Conservation: Preliminary Results." eLearning Papers 25.

Lombardi, D., and G. M. Sinatra. 2013. "Emotions about Teaching about Human-Induced Climate Change." International Journal of Science Education 35 (1):167-91. doi: 10.1080/09500693.2012.738372

Lorenzoni, I., S. Nicholson-Cole, and L. Whitmarsh. 2007. "Barriers Perceived to Engaging with Climate Change among the UK Public and Their Policy Implications." Global Environmental Change 17 (3-4):445-59. doi:10.1016/ j.gloenvcha.2007.01.004

McGonigal, J. 2011. Reality is Broken. Why Games Make Us Better and How They can Change the World. New York: The Penguin Press.

McNaught, C., and P. Lam. 2010. "Using Wordle as a Supplementary Research Tool." The Qualitative Report 15 (3): 630-43.

Mitgutsch, K., and N. Alvarado. 2012. "Purposeful by Design? A Serious Game Design Assessment Framework." Proceedings of the International Conference on the Foundations of Digital Games. New York, 121-128.

Morris, B. J., S. Croker, C. Zimmerman, D. Gill, and C. Romig. 2013. "Gaming Science: The "Gamification of Scientific Thinking". Frontiers in Psychology 4:1-16. doi:10.3389/fpsyg.2013.00607

Moser, S. C. 2010. "Communicating Climate Change: History, Challenges, Process and Future Directions." WIREs Climate Change 1 (1):31-53. doi:10.1002/wcc.011

ONeill, S., and S. Nicholson-Cole. 2009. "Fear Won't Do It" Promoting Positive Engagement with Climate Change through Visual and Iconic Representations." Science Communication 30 (3):355-79. doi: 10.1177/ 1075547008329201

Onwuegbuzie, A. J., and N. L. Leech. 2007. "Sampling Designs in Qualitative Research: Making the Sampling Process More Public." The Qualitative Report 12 (2):238-54.

Ouariachi, T., M. D. Olvera-Lobo, and J. Gutiérrez-Pérez. 2017. "Analyzing Climate Change Communication through Online Games: development and Application of Validated Criteria." Science Communication 1 (31):1-31. doi: $10.1177 / 1075547016687998$

Parant, A., A. Pascual, M. Jugel, M. Kerroume, M.-L. Felonneau, and N. Guéguen. 2017. "Raising Students Awareness to Climate Change: An Illustration with Binding Communication." Environment and Behavior 49 (3):339-53. doi: $10.1177 / 0013916516629191$

Pendergast, D. 2010. "Connecting with Millennials: Using Tag Clouds to Build a Folksonomy from Key Home Economics Documents." Family \& Consumer Sciences Research Journal 38:289-302.

Plutzer, E., M. McCaffrey, A. L. Hannah, J. Rosenau, M. Berbeco, and A. H. Reid. 2016. "Climate Confusion among US Teachers." Science 351 (6274):664-5. doi:10.1126/science.aab3907

Prensky, M. 2001. "Digital Natives, Digital Immigrants." On the Horizon 9 (5):1-6. doi:10.1108/10748120110424816

Przybylski, A. K., N. Weinstein, K. Murayama, M. F. Lynch, and R. M. Ryan. 2012. "The Ideal Self at Play: The Appeal of Video Games That Let You Be All You Can Be." Psychological Science 23 (1):69-76. doi:10.1177/ 0956797611418676 
Schneider, J., and S. Schaal. 2017. "Location-Based Smartphone Game in the Context of Environmental Education and Education for Sustainable Development: fostering Connectedness to Nature with Geogames." Environmental Education Research 23 (9):1-14. doi: 10.1080/13504622.2017.1383360

Schoenau-Fog, H. 2011. "The Player Engagement Process-an Exploration of Continuation Desire in Digital Games." Proceedings of DiGRA Conference: Think Design Play, 4-18.

Soekarjo, M., and H. van Oostendorp. 2015. "Measuring Effectiveness of Persuasive Games Using an Informative Control Condition." International Journal of Serious Games 2 (2):6-20.

Stevenson, K. T., M. N. Peterson, and A. Bradshaw. 2016. "How Climate Change Beliefs among US Teachers Do and Do Not Translate to Students." PLoS One 11 (9): e0161462 doi: 10.1371/journal.pone.0161462

Strauss, A. L., and J. M. Corbin. 1990. Basics of Qualitative Research: Grounded Theory Procedures and Techniques. Newbury Park, CA: Sage Publications.

van der Linden, S., E. Maibach, and A. Leiserowitz. 2015. "Improving Public Engagement with Climate Change: Five "Best Practice" Insights from Psychological Science." Perspectives on Psychological Science 10 (6):758-63. doi: $10.1177 / 1745691615598516$

Weitze, C. L. 2014. "Developing Goals and Objectives for Gameplay and Learning". In Learning, education and games: Volume One: Curricular and design Considerations, edited by K. Schrier, 225-249. Pittsburgh, PA: Carnegie Mellon University ETC Press.

Whitmarsh, L., S. O'Neill, and I. Lorenzoni. 2013. "Public engagement with climate change: What do we know and where do we go from here?". International Journal of Media \& Cultural Politics 9 (1):7-25. doi: 10.1386/ macp.9.1.7_1

Wu, J., and J. Lee. 2015. "Climate Change Games as Tools for Educational and Engagement." Nature Climate Change 5 (5):413-8. doi:10.1038/NCLIMATE2566

Yang, J. C., Y. L. Lin, and Y. C. Liu. 2016. "Effects of Locus of Control on Behavioral Intention and Learning Performance of Energy Knowledge in Game-Based Learning." Environmental Education Research 23 (6):886-99. doi:10.1080/13504622.2016.1214865

Yee, N. 2006. "Motivations for Play in Online Games." Cyberpsychology \& Behavior 9 (6):772-5. 